\title{
ANALYSIS OF MULTISPECTRAL IMAGERY FROM UNMANNED AERIAL VEHICLE (UAV) USING OBJECT-BASED IMAGE ANALYSIS FOR DETECTION OF Ganoderma DISEASE IN OIL PALM
}

\author{
IZZUDDIN, M A*; HAMZAH, A**; NISFARIZA, M N and IDRIS, A S*
}

\begin{abstract}
Ganoderma disease that affects oil palms has caused huge losses to the palm oil industry in Malaysia. To curb widespread infection and mitigate further losses, attempts have been made to detect infected oil palms automatically so that they can be treated or destroyed. The multispectral remote sensing technology can be employed to this effect efficiently. From the aerial images, infected oil palms can be detected and classified according to the Ganoderma Disease Severity Index (GDSI). In this study, object-based image analysis (OBIA) was performed to classify oil palms in a selected area into three classes namely; healthy (T0), moderately infected (T2) and severely infected (T3). It would be desirable if lightly infected oil palms could also be categorised as a class. However, it was extremely difficult to discriminate lightly infected oil palms from the healthy ones just by analysing the aerial images since symptoms of early infection were not evident in the fronds yet. Images of each individual band as well as those obtained by combining two, three or four bands of the available spectra were analysed. The OBIA was conducted using example-based feature extraction procedure and various OBIA settings were tested to achieve a number of classification results. The accuracies of the results are quantified by comparing the results with the ground truth data. The results suggest that the combination of Edge-based segmentation and merge algorithm using Full-Lambda Schedule (FLS), Support Vector Machine (SVM) classifier and three-band data of (G_R_NIR) scores the highest accuracy of (91.8\%). When data of individual bands were tested using the same algorithm and classifier, they obtained moderate accuracies ranging from 65.5\%-76.2\%. However, when data of two, three and four bands were combined, better results with classification accuracies from $70 \%-90 \%$ were recorded. These results show that the OBIA can be used to analyse multispectral images of oil palms to detect moderate and severe infection of Ganoderma disease. Detection of early infection of Ganoderma is feasible if more advanced algorithms and classifiers can be used with multispectral and hyperspectral aerial images.
\end{abstract}

Keywords: multispectral, Ganoderma, object-based image analysis, support vector machine, unmanned aerial vehicle.

Date received: 21 May 2019; Sent for revision: 21 May 2019; Accepted: 27 September 2019; Available online: 30 June 2020.

\footnotetext{
Malaysian Palm Oil Board,

6 Persiaran Institusi, Bandar Baru Bangi,

43000 Kajang, Selangor, Malaysia.

E-mail: mohamad.izzuddin@mpob.gov.my

** Department of Electrical Engineering,

Faculty of Engineering, Universiti Malaya,

Jalan Universiti, 50603 Kuala Lumpur, Malaysia.

₹ Department of Geography,

Faculty of Arts and Social Sciences, Universiti Malaya,

Jalan Universiti, 50603 Kuala Lumpur, Malaysia.
}

\section{INTRODUCTION}

The oil palm has been a major contributor to oils and fats production compared to other vegetation oil such as soyabean and rapeseed oil. The total export revenue from oil palm products in 2017 was RM 77.85 billion, an increase of about $14.62 \%$ from year 2016 revenue (RM 67.92 billion). The oil palm 
industry significantly contributed to Malaysia's gross domestic product (GDP), gross national income (GNI), foreign exchange and employment (Kushairi et al., 2018). But the oil palm (Elaeis guineensis) is vulnerable to several diseases. The main disease that threatens oil palm and causes economic loss in Malaysia and Indonesia is Ganoderma disease caused by Ganoderma boninense fungus (Idris et al., 2002; 2014; Roslan and Idris, 2012).

Current works on the detection of Ganoderma disease infection in oil palms mainly focus on ground-based sampling of individual oil palms in the field and laboratory-based analyses (Madihah et al., 2014). The assessment of the Ganoderma disease is made by visual inspection of the appearance of Ganoderma mycelium, small white button, fruiting bodies or stem and bole rotting at the palm base. Foliar symptoms such as yellowing and drying of leaves and skirting of lower fronds of the oil palm canopy is also important (Rees et al., 2007; Nuranis et al., 2016; Idris et al., 2016). The ground census method is labour-intensive and time-consuming. It is difficult to accurately estimate the regional distribution and severity of the disease in large area within a short time. Furthermore, visual assessment is subjective and different workers might classify the severity of infected palms differently.

In large plantation areas with millions of oil palms, a large-scale approach that is fast and cheap is more practical since assessment must be done periodically to estimate the pattern of spread of the disease and the effectiveness of the control strategy employed. A viable approach that can be used for detecting Ganoderma infection is by analysing aerial view of the oil palm plantation area. It is fast since a sortie of an Unmanned Aerial Vehicle (UAV) with a camera can cover a large area. Although Ganoderma disease only affects the root and base of the oil palm stem, a study by Haniff et al. (2005) shows that the root of an oil palm infected by Ganoderma triggers chemical signaling such as by releasing abscisic acid (ABA) produced by its dehydrating roots even when the water status in the field is kept constant. This chemical signal causes stomata closure which results in reduction of stomatal conductance that is highly correlated with photosynthesis. These physiological changes in the oil palm foliar cause changes in the spectral properties of the oil palm canopy. Over time, variations in the spectral properties of the canopy will become detectable by analysing the multispectral images of its aerial view (Yang et al., 2010; Johansen et al., 2018; Albetis et al., 2019).

In the last two decades, aerial image analysis has been widely used for various agricultural applications including detection of fungal, bacterial and insect related diseases in plants (Shafri and Hamdan, 2009; Mahlein et al., 2010; Lelong et al., 2010). Fungi and bacteria usually attack plants at their molecular, tissue and cellular levels. The attack alters the reflectance values of green $(G)$, red $(R)$, red edge (RE) and near-infrared (NIR) regions of the foliar spectrum of the plants (Yang et al., 2010; Gupta, 2010). The spectral changes become key indicators that differentiate between healthy and infected plants. Leckie et al. (2005) found that NIR, R and blue (B) bands were most useful in detecting jack pines infected by worms. Ratios of bands notably produced better classification results than single bands, with a Normalised Difference Vegetation Index (NDVI) or R/NIR ratio being the best.

The $\mathrm{G}$ band corresponds to the reflected energy in the 530-570 $\mathrm{nm}$ spectral band and the reflectance peak is at around $550 \mathrm{~nm}$. This spectral band is often strongly correlated with leaf chlorophyll content. The $\mathrm{R}$ band corresponds to the reflected energy in the 640-680 nm spectral band. The strong absorption in this band results in low reflectance. Reflectance varies significantly in relation to factors such as biomass, leaf area index (LAI), soil minerals, humidity and plant stress (Rees, 2013; Richards, 2013). Meanwhile, the RE band (730-740 nm) is a very narrow and it corresponds to the rapid change from low $\mathrm{R}$ reflectance to high NIR reflectance. This band is very sensitive to plant stress and provides information on the chlorophyll and nutrient status of the plant. Moreover, an increase in the reflectance of this band often observed when the plant is under nutrient stress (Campbell, 2002).

This RE band can be regarded as the transition zone of steep change in reflectance between the strong chlorophyll absorption near $680 \mathrm{~nm}$ and strong scattering by leaf cell structure near $750 \mathrm{~nm}$. The value of this change was measured on leaves of various species by taking the derivative of the reflectance spectrometry (Haboudane et al., 2002). The RE can also indicate the status of chlorophyll content, biomass and hydric for a plant (Filella and Penuelas, 1994). Several studies have discussed the methodology in obtaining the RE in vegetation (Carter and Knapp, 2001; Cho and Skidmore, 2006; Vincini and Frazzi, 2011).

The NIR band, which corresponds to the wavelength range of $770-810 \mathrm{~nm}$, has the strongest reflectance of the bands studied. This band is sensitive to plant vigour and crop type. Pigments such as chlorophyll do not influence the NIR so it is often used to normalise chlorophyll-sensitive wavebands. Moreover, a reduction of the reflectance in this band results when a plant is under stress.

A similar approach of using multispectral aerial images can be used to detect and classify oil palms that have been infected by Ganoderma. To date, several studies on Ganoderma disease detection in oil palms have been carried out using multispectral aerial images (Izzuddin et al., 2017; Parisa et al., 2017; Santoso et al., 2011; 2018). Izzuddin et al. (2017a) studied the application of multiband (RGB and NIR) digital number (DN)-based images with no spectral 
reflectance acquired from UAV to detect Ganoderma infected oil palms. They used conventional and advanced classifiers such as Maximum Likelihood (ML), Parallelepiped (P), Neural Networks (NN) and Support Vector Machines (SVM) to classify healthy and Ganoderma-infected oil palm. Poor to moderate classification accuracies $(20 \%-40 \%)$ were reported when individual and combinations of bands were used to detect oil palms infected by Ganoderma.

In a similar study, Santoso et al. (2018) employed high-resolution multispectral WorldView 3 (WV-3) satellite images to classify healthy and Ganoderma infected oil palms into four categories. The reflectance values from eight bands of WV-3 images were used to classify the severity of infected oil palms in a selected plantation. A Decision Tree (DT), Random Forest (RF) and SVM were utilised as a classifier. The oil palms were first classified into healthy or infected category. Then, depending on the severity of the disease, infected oil palms were further classified as early, moderately or severely infected. When all bands were used together with band number four as a correction band, $54.1 \%$, $53.3 \%$ and $53.1 \%$ classification rates were achieved for SVM, DT and RF classifier, respectively.

Using all-bands available may not produce the best classification result if multicollinearity exists among the bands. Collinearity is the situation where two or more predictor variables in a statistical model are linearly related (Dormann et al., 2013). Thus, only significant bands and band combinations should be used to reduce redundancy and multicollinearity (Patel and Kaushal, 2011). Techniques like Principal Component Analysis and Optimum Index Factor can be employed to select the best bands to use with an advanced classifier such as SVM, NN, DT, or RF (Mokhtari et al., 2013; Salgadoe et al., 2018; Huang et al., 2018; Puliti et al., 2018; Mulley et al., 2019; Heim et al., 2019).

The advancement of image processing technique has introduced the object-based image analysis (OBIA) technique that integrated the image segmentation algorithm and advance image classifier such as SVM (Blaschke, 2010). The OBIA was introduced to solve the problem of mixed-pixel that usually produce misclassification of features of interest in the image and false-positive results that reduce the accuracy of the image classification (Li et al., 2014). One of widely used segmentation algorithm is the watershed segmentation (Kavzoglu and Tonbul, 2017).

The watershed segmentation has been used to segment features such as crops and vegetations (Roerdink et al., 2001; Jing, 2009; Ballanti et al., 2016; Rizeei et al., 2018). In segmentation, pixels in the image were grouped into non-overlapping homogeneous regions based on some criteria. Image classification was conducted after segmentation process. The SVM classifier is one of good classifier that been used in many crop and plant diseases studies (Pujari et al., 2016; Rahman et al., 2017; Huang et al., 2018; Turkoglu and Hanbay, 2019). The SVM is a supervised learning binary classifier and is based on the structural risk minimisation principle. The non-linear structures can be modeled by transferring the space of input data into a high dimension space through kernel trick. The selection of kernel type is important to achieve good classification accuracy. The SVM usually uses one of four basic kernels, which are linear, polynomial, sigmoid and radial basis function (Gholami and Fakhari, 2017).

The high spatial resolution of multispectral image from UAV provides detailed physical conditions of oil palm canopy fronds, leaflets and spears and also spectral information from the $G, R$, RE and NIR bands. But no extensive studies have been made on the multispectral image using the OBIA analysis for detection of Ganoderma disease in oil palm. Therefore, the objective of this study was to classify Ganoderma infected oil palms in a plantation area into three classes according to its severity using OBIA. This was achieved by analysing multispectral aerial images acquired by a UAV with a multispectral camera.

\section{MATERIALS AND METHODS}

The flow chart of the methodology of the study is shown in Figure 1.

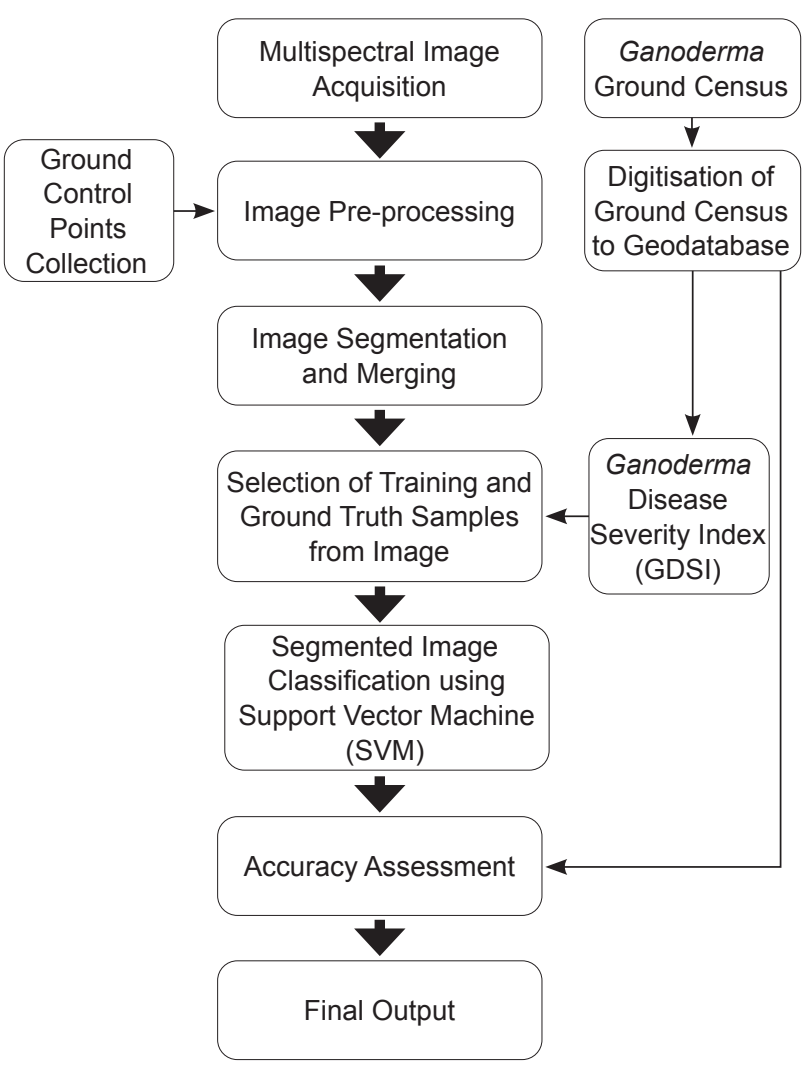

Figure 1. Flow chart of methodology. 


\section{Study Area}

The study plot was located in an oil palm plantation in Lekir, Perak, Malaysia (4 $6^{\prime} 42^{\prime \prime} \mathrm{N}$ and $100^{\circ} 53^{\prime} 12^{\prime \prime}$ E) as shown in Figure 2. Its annual precipitation was $2256 \mathrm{~mm}$ and average daily temperature was between $24^{\circ} \mathrm{C}$ and $34^{\circ} \mathrm{C}$. The size of the area was estimated to be around 4 ha and planted with dura x pisifera (DxP) oil palms. The planting density of the plot was 160 oil palms ha ${ }^{-1}$ and the age of the oil palms was 16 years old. The area was on a flat terrain and had no other diseases nor pest infestation and nutrient deficiencies.

\section{Ground Data Collection}

The ground data collection involved fieldworks to record Ganoderma disease census and collection of geographic coordinates using Global Positioning System (GPS) device to plot the study area in spatial database and image geometric correction purposes. The Ganoderma disease census in the field was conducted for a duration of five days in April 2018 during the UAV image acquisition campaign. The oil palms were categorised into Ganoderma disease severity index (GDSI) as healthy (T0), early (T1), moderately infected (T2) and severely infected (T3) (Table 1). The manual categorisation carried out during ground census was based on visual symptoms of the disease on the oil palms (Table 1) (Idris et al., 2016).

\section{Multispectral Image Acquisition}

The multispectral images were acquired from the study area using a Parrot Sequoia multispectral camera system that was mounted on a DJI Phantom Matrice, a light-weight quadcopter-type UAV.

The multispectral camera was developed and manufactured by Parrot Sequioa (Parrot Drones SAS), USA. The system provides multispectral images of four bands with bandpass (BP), which are: 1. G [550 nanometre (nm) BP 40]; 2. R (660 nm BP 40); 3. RE (735 nm BP 10) and 4. NIR (790 nm BP 40). The ground spatial resolution is $0.2 \mathrm{~m}$ at $100 \mathrm{~m}$ of flight altitude. The images were acquired on 2 April 2018 between 10.00 am to 11.00 am local time during sunny day and clear sky.

TABLE 1. THE Ganoderma DISEASE SEVERITY INDEX (GDSI)

\begin{tabular}{|c|c|c|}
\hline Index & Category & Description \\
\hline T0 & Healthy & $\begin{array}{l}\text { No presence of Ganoderma fruiting bodies, } \\
\text { no foliar symptoms and rotting at the base } \\
\text { of stem, negative results of Ganoderma } \\
\text { selective medium (GSM) and polymerase } \\
\text { chain reaction (PCR)-DNA test. }\end{array}$ \\
\hline $\mathrm{T} 1$ & Early & $\begin{array}{l}\text { Oil palm looks healthy, no foliar symptoms } \\
\text { but presence of white mycelium of } \\
\text { fruiting bodies of Ganoderma at the base of } \\
\text { stem, positive results of Ganoderma using } \\
\text { GSM or PCR-DNA test. }\end{array}$ \\
\hline $\mathrm{T} 2$ & Moderate & $\begin{array}{l}\text { Presence of white mycelium of fruiting } \\
\text { bodies of Ganoderma at the base of stem, } \\
\text { existence of foliar symptom such as } \\
\text { yellowing and lowering of older fronds } \\
(<30 \%) \text {. Existence of rotting at the base of } \\
\text { stem }(<30 \%) \text {, positive results of Ganoderma } \\
\text { using GSM or PCR-DNA test. }\end{array}$ \\
\hline T3 & Severe & $\begin{array}{l}\text { Presence of white mycelium of fruiting } \\
\text { bodies of Ganoderma at the base of stem. } \\
\text { Severe foliar symptom }(>30 \%) \text {. Existence } \\
\text { of rotting at the base of stem }(>30 \%) \text {, } \\
\text { positive results of Ganoderma using GSM } \\
\text { or PCR-DNA test. }\end{array}$ \\
\hline
\end{tabular}
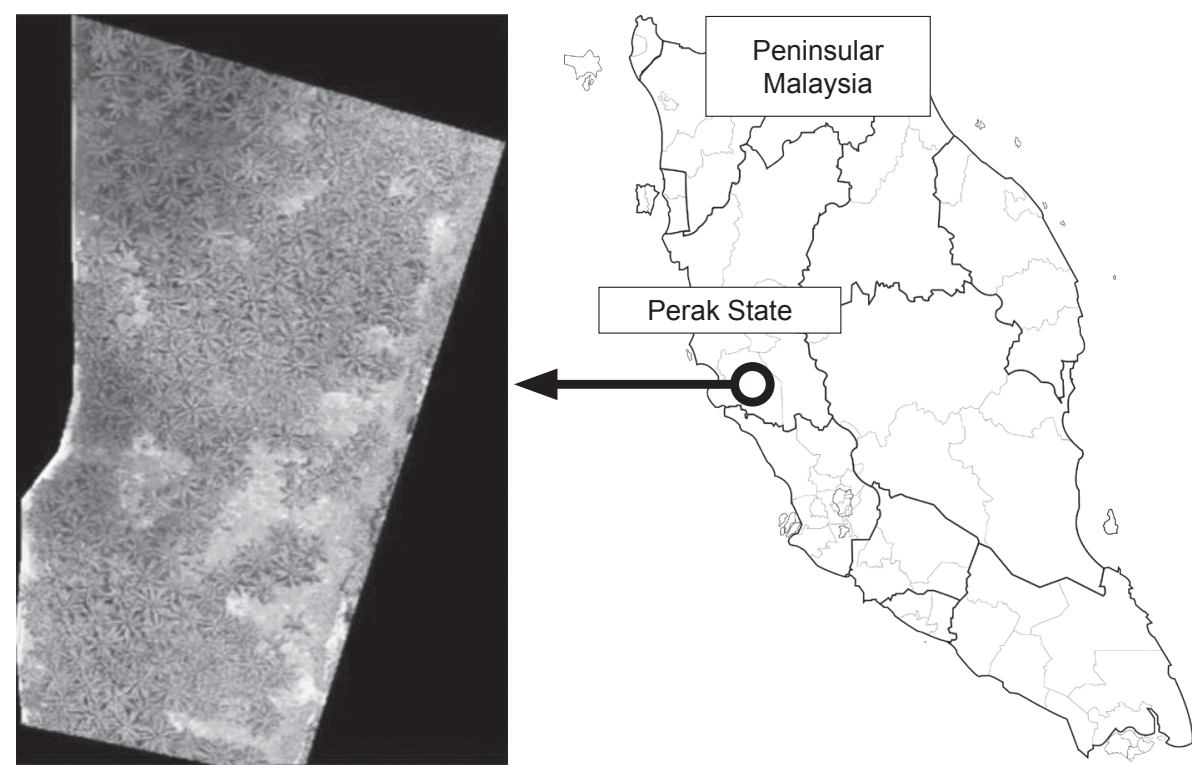

Figure 2. Aerial photo captured by Sequoia camera onboard unmanned aerial vehicle (UAV) and location of study area. 


\section{Pre-processing}

The raw multispectral images were radiometrically calibrated to radiance and then atmospherically corrected to reflectance using standard operation procedure provided in Pix4D software (Pix4D, 2019). The final reflectance values were measured in percentage unit (0\%-100\%). The calibrated data were then georeferenced using ground coordinate obtained from GPS and inertial measurement unit (IMU) information.

\section{OBIA on Multispectral Image}

The OBIA was integrated with the image segmentation and followed by advanced image classification. In this study, Example-based Feature Extraction toolbox in Environment for Visualising Image (ENVI) (version 5.0, Harris Geospatial Solutions Inc., Broomfield, CO, USA) software was used to conduct the OBIA.

In this study, the Edge-based watershed segmentation algorithm with three parameters namely Scale Level, Merge Level and Texture Kernel Size (TKS), was applied (Roerdink et al., 2001). The optimal segmentation parameter setting was set by trial-and-error where the best parameter values were defined via visual assessment of the segmented image outputs. After the segmentation process, all attributes generated by segmentation process were selected to be used as class predictors in the classification process. The segments in the segmented image were selected and combined to represent individual oil palm canopies and then categorised into the GDSI. The combined segments of the oil palm canopy for each GDSI was used as training samples for the SVM classifier. The SVM classifier was selected because other studies have shown that SVM provide higher accuracy compared to other non-parametric advance classifiers such as NN and regression tree (RT) (Shafri and Ramle, 2009; Shao and Lunetta, 2012; Noi and Kappas, 2018).

Shao and Lunetta (2012) had classified MODIS time series multispectral satellite imagery for land cover characterisation using SVM, NN classifiers and classification and regression tree (CART) technique. Their results showed that the SVM generated good overall accuracies ranging from $77 \%-80 \%$ for training sample sizes from $20-800$ pixels per class, compared to $67 \%-76 \%$ and $62 \%-73 \%$ for $\mathrm{NN}$ and CART, respectively. These results indicated that the SVM had good generalisation method although using small training sample sizes. They also concluded that SVM showed less variability in accuracy when classification trials were repeated using different training sample sets.

\section{Accuracy Assessment}

The accuracy of VI outputs were then assessed using comparison of OBIA output image with the ground truth and also confusion matrix. The comparison of OBIA outputs and ground truth was conducted using following formula:

\section{$\frac{\text { Number of true positive }}{\text { Number of ground truth }} \times 100=$ Overall accuracy $(\%)$}

Other than that, confusion matrix was also used to determine the Kappa coefficient of the classification. The confusion matrix compares the observed from image classification outputs and expected from the ground census data and provides the percentage of similarity of image output compared to actual ground census in term of overall accuracy in percentage value. The overall accuracy is calculated by summing the number of pixels classified correctly based on ground truth and divide by the total number of pixels (Kohavi and Provost 1998). The overall accuracy was also cross-checked using Kappa coefficient. The interpretation of Kappa coefficient values for classification accuracy classes is shown in Table 2 (Viera and Garrett 2005).

TABLE 2. KAPPA COEFFICIENT DESCRIPTION TABLE

\begin{tabular}{cl}
\hline Kappa coefficient & \multicolumn{1}{c}{ Description } \\
\hline$<0$ & Less than chance agreement \\
$0.01-0.20$ & Slight agreement \\
$0.21-0.40$ & Fair agreement \\
$0.41-0.60$ & Moderate agreement \\
$0.61-0.80$ & Substantial agreement \\
$0.81-0.99$ & Almost perfect agreement \\
\hline
\end{tabular}

\section{RESULTS AND DISCUSSION}

\section{Pre-processing Output}

The set of raw images acquired from the UAV was radiometrically corrected and georeferenced with Rectified Skewed Orthomorphic (RSO) projection of West Malaysia with Kertau 48 as datum for each individual band. Then, the images were orthorectified to correct skewness of features in the images. The orthorectified images were then mosaiced to represent the whole study area. The mosaiced image of each individual band was displayed in one-band grayscale mode (Figure 3).

The mosaiced image was then overlaid onto each other and merged into a single image with four multispectral bands. The coloured display of the multispectral band can be visualised by combination of three bands. Figure $4 a$ shows the mosaiced coloured image with band combination of G, R and NIR. 


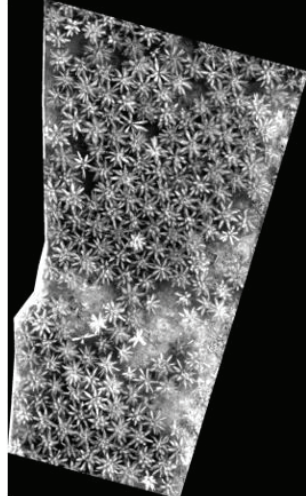

(a)

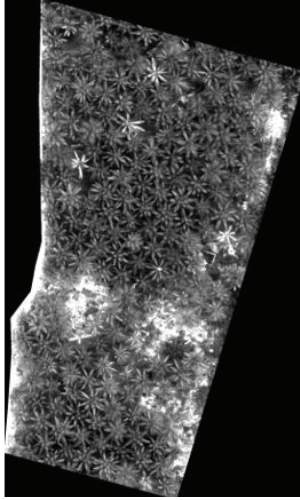

(b)

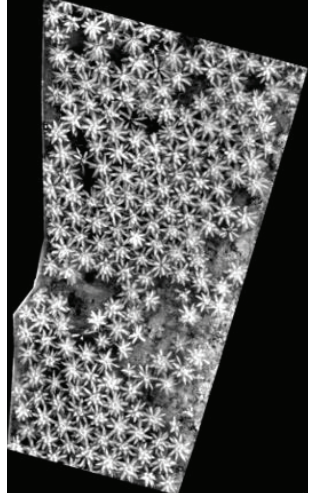

(c)

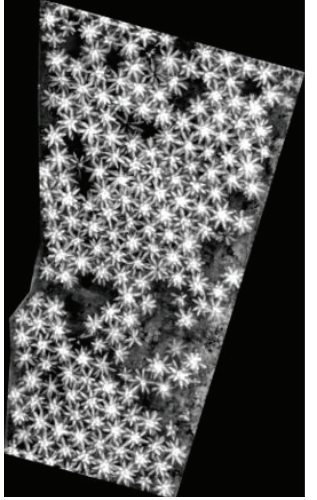

(d)

Figure 3. List of individual pre-processed image bands acquired from Sequoia multispectral (a) green $(G),(b)$ red $(R),(c)$ red edge $(R E)$, and (d) near infrared (NIR).

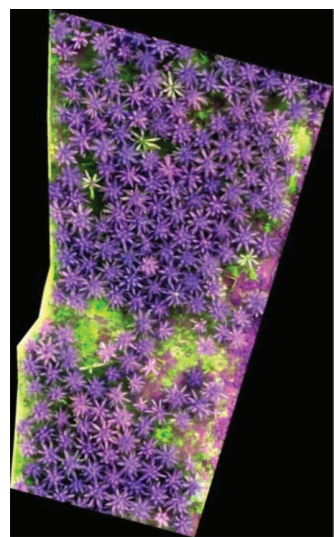

(a)

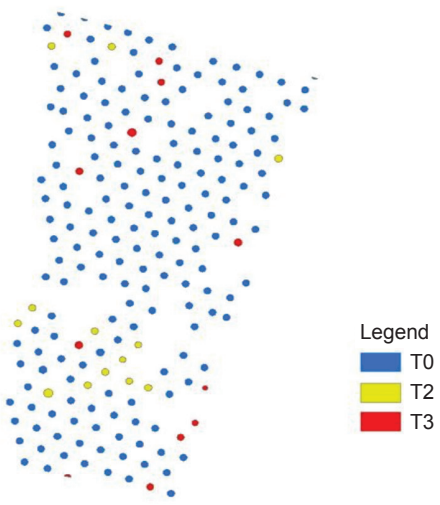

(b)

Figure 4. (a) Pre-processed image acquired by Sequioa camera (band combination: green, red, near-infrared) and (b) ground census of Ganoderma Disease Severity Index (GDSI).

In this study, the analysis was conducted on individual band, two-band combinations, threeband combinations and all-bands combinations (Table 3). The different combinations of multispectral bands are also useful to enhance the image classification accuracy (Momeni et al., 2016; Xie et al., 2019).

\section{Ground Census}

The ground census of individual oil palm that has been recorded in the field based on visual assessment and categorised into the GDSI was digitised into their respective coordinates and the attributes of GDSI were tagged to each of the individual oil palm points as shown in Figure $4 b$. The total number of oil palm inspected during the ground census was 208 oil palms.

\section{OBIA Outputs}

In OBIA process, the pre-processed images were analysed using separated four individual-bands and 11 different band combinations. Firstly, each of the image combination as listed in Table 3 was segmented using watershed segmentation method in ENVI 5.0 software. Several trial-and-error testing for selection of the best values for the Segment and Merging processes was conducted and the results showed that the best Segment was Edge-based with Scale Level value of 50 and Merging was best conducted by using FLS algorithm with Merge Level of 60 while the TKS value was set to 3 (Figure $5)$. The values were selected because they could provide good delineation of the oil palm canopy and fronds and minimised the over segmentation problems. The segmented images were then used as input image for further SVM classification.

Then, SVM classification was conducted on the segmented image for each band combinations. There were 30, 8 and 7 oil palms for T0, T2 and T3 selected as training sample for the SVM classification. The training samples for T1 was not included for classification because there were only two palms confirmed fitting the description for the T1 category and not enough as input for the classifier. The training samples were selected randomly and well-distributed in the study area. The SVM was preferable compared to other classifiers due to several reports suggesting that SVM provided better classification accuracy for multispectral imageries (Pal and Mather, 2005; Ballanti et al., 2016). 
TABLE 3. LIST OF INDIVIDUAL BAND AND DIFFERENT BAND COMBINATIONS

\begin{tabular}{ccccc}
\hline No. & Individual-band & $\begin{array}{c}\text { Two-band } \\
\text { combinations }\end{array}$ & $\begin{array}{c}\text { Three-band } \\
\text { combinations }\end{array}$ & $\begin{array}{c}\text { Four-band } \\
\text { combinations }\end{array}$ \\
\hline 1 & G & G_R & G_R_RE & G_R_RE_NIR \\
2 & R & G_RE & G_R_NIR & - \\
3 & RE & G_NIR & R_RE_NIR & - \\
4 & NIR & R_RE & G_RE_NIR & - \\
5 & - & R_NIR & - & - \\
6 & - & RE_NIR & - & - \\
\hline
\end{tabular}

Note: G - green band, R - red band, RE - red edge band, NIR - near infrared band.

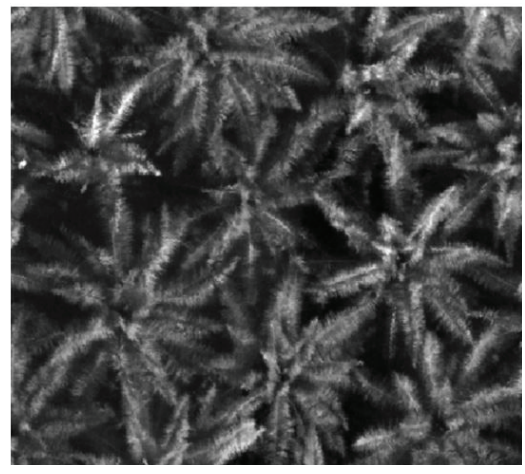

(a)

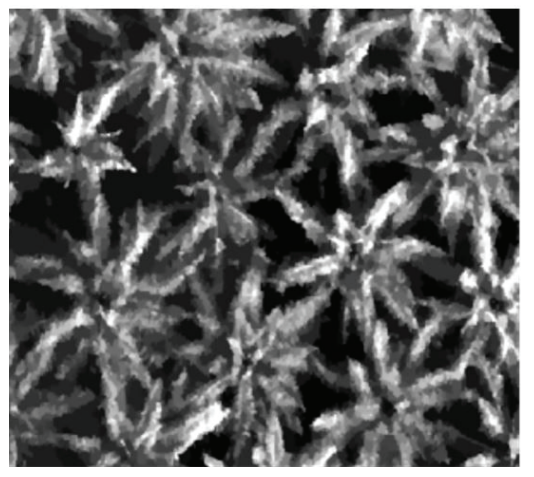

(b)

Figure 5. Outputs of segmentation process (a) original image, and (b) segmented image.

The output images of the SVM classification were presented in pseudo-colour images consisted of T0 (blue), T2 (yellow), T3 (red) and background (dark) (Figure 6). The setting for SVM classifiers was conducted based on trial-and-error until a good classification accuracy was achieved. The SVM parameters setting in this study were Radial Basis Function (RBF) as Kernel Type, the Gamma in Kernel Function (GiKF) was set to 0.333 with 100 penalty parameters. The Degree of Kernel Polynomial (DoKP) was set to 1 and Bias in Kernel Function (BiKF) was set to 1.00. The threshold was set to 5, indicating 95\% of confidence level for classification. The analysis also allowed unclassified to classify the unknowns into another class to reduce the errors that existed during classification.

The classification outputs were assessed for their accuracy by comparison of OBIA output with the ground census and measured in percentage of accuracy and kappa coefficient generated from confusion matrix (Table 4). The results of SVM classification showed that there were eight different band combinations, which produced good accuracy (>80\%); they were: 1) R_NIR; 2) G_NIR; 3) RE_NIR; 4) G_R_RE; 5)G_R_NIR; 6) R_RE_NIR;7)G_RE_NIR; 8) G_R_RE_NIR. The results shown in Table 4 revealed that G_R_NIR has the highest overall accuracy (91.8\%) followed by G_R_RE_NIR (89.3\%). The results also showed that classification of individual band alone provided moderate classification with overall accuracy between $65.5 \%$ and $76.2 \%$ only. The results also showed that the classification accuracy of T3 was lower than T2. The problem occurred when there were several palms confirmed as T3 from the ground census but were classified as T2 by the classifier. This scenario occurred due to redundancy or similarity of spectral properties from training samples of T2 and T3.

Our results showed that using two and more band combinations enabled SVM classifier to enhance the sensitivity of detecting spectral changes that were triggered by biophysical changes in the oil palm canopy as mentioned by Haniff et al. (2005). Shafri and Ramle (2009) also found that classification of land use and land cover from multispectral remote sensing satellite using SVM classifier provided better overall accuracy of $73 \%$ compared to Decision Tree (DT) classifier with only $69 \%$ overall accuracy. Other than that, Noi and Kappas (2018) also suggested that SVM produced higher overall accuracy (90\%95\%) compared to Random Forest (RF) and $\mathrm{k}$ Nearest Neighbour (kNN) classifier for land cover classification.

Each spectral band has specific response to plants biophysical changes. The $\mathrm{G}$ band is sensitive to plant/ leaf nitrogen and pigment. While, the $R$ band is sensitive to chlorophyll $a$ and $b$ content. The RE band is sensitive to plant stress and chlorophyll content and NIR is sensitive to water content, moisture and biomass of plant (Thenkabail et al., 2016). 


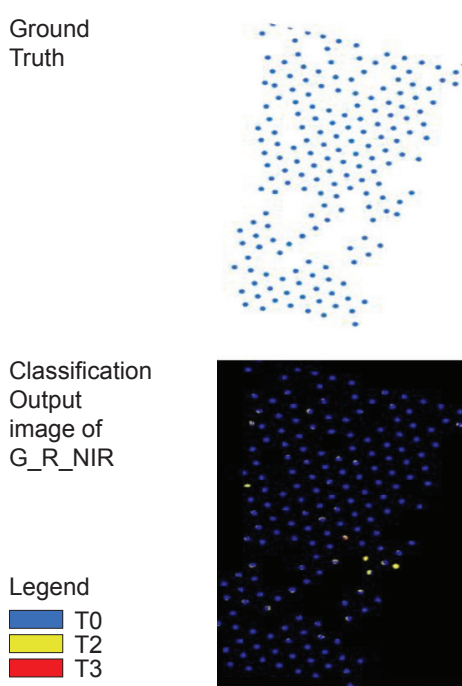

(a)

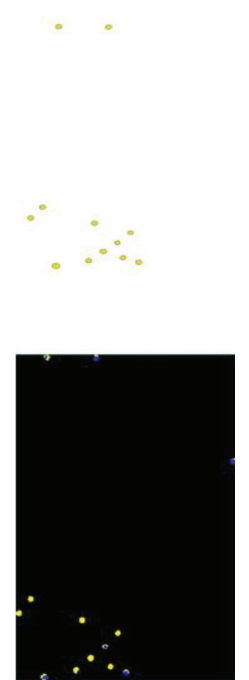

(b)

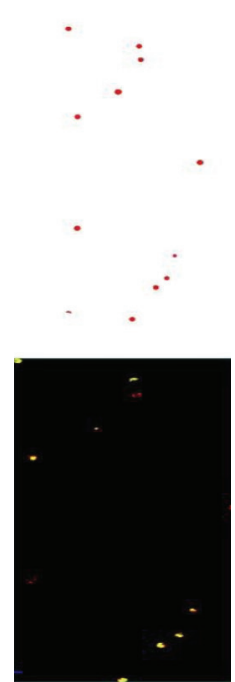

(c)

Figure 6. Visual comparison of the best object-based image analysis (OBIA) classification output image of three-band combination image (G_R_NIR) with ground truth data: (a) T0, (b) T2 and (c) T3.

TABLE 4. ACCURACY ASSESSMENT OF CLASSIFICATION OUTPUT FOR INDIVIDUAL BAND AND DIFFERENT BAND COMBINATIONS

\begin{tabular}{|c|c|c|c|c|c|c|}
\hline \multirow{2}{*}{ Band combinations } & \multicolumn{5}{|c|}{ Category accuracy $(\%)$} & \multirow{2}{*}{ Kappa coefficient } \\
\hline & Rank & T0 & $\mathrm{T} 2$ & T3 & Overall accuracy $(\%)$ & \\
\hline G & 11 & 72.9 & 38.5 & 33.3 & 68.4 & 0.6439 \\
\hline $\mathrm{R}$ & 10 & 75.1 & 53.9 & 33.3 & 71.3 & 0.6341 \\
\hline RE & 13 & 75.1 & 84.6 & 83.3 & 76.2 & 0.6215 \\
\hline NIR & 12 & 66.9 & 46.2 & 66.7 & 65.5 & 0.4061 \\
\hline G_R & 14 & 81.3 & 61.5 & 66.7 & 79.1 & 0.6121 \\
\hline G_RE & 8 & 79.6 & 69.2 & 50 & 77.2 & 0.8990 \\
\hline G_NIR & 4 & 93.4 & 69.2 & 50 & 89.3 & 0.9430 \\
\hline R_RE & 9 & 74.6 & 53.8 & 41.7 & 71.4 & 0.3237 \\
\hline R_NIR & 5 & 91.7 & 61.5 & 41.7 & 86.9 & 0.9383 \\
\hline RE_NIR & 2 & 92.8 & 84.6 & 75 & 91.3 & 0.7396 \\
\hline G_R_RE & 7 & 85.1 & 76.9 & 41.7 & 82.0 & 0.8693 \\
\hline G_R_NIR & 1 & 95.03 & 76.9 & 58.3 & 91.8 & 0.9426 \\
\hline R_RE_NIR & 4 & 90.6 & 84.6 & 33.3 & 86.9 & 0.9665 \\
\hline G_RE_NIR & 6 & 87.8 & 84.6 & 58.3 & 85.9 & 0.7929 \\
\hline G_R_RE_NIR & 3 & 93.4 & 76.9 & 41.7 & 89.3 & 0.8941 \\
\hline
\end{tabular}

Our results showed that for individual band, the RE band showed the highest accuracy $(76.2 \%)$, followed by R band (71.3\%), G band $(68.4 \%)$ and NIR band $(65.5 \%)$. Our results also suggested that the difference between GDSI was mainly influenced by the plant stress and reduction of chlorophyll $\mathrm{a}$ and $\mathrm{b}$ content detected by RE and $\mathrm{R}$ bands and followed by plant/leaf nitrogen and pigment reduction detected by $\mathrm{G}$ band. There were a smaller number of palms suffered from reduction of water content, moisture and biomass as detected in NIR band because majority of the palms in the study area were in healthy and moderate infection condition.

The RE band showed significant influence in Ganoderma disease detection as reported by other crop disease studies (Fahrentrapp et al., 2019; Heim et al., 2019). Fahrentrapp et al. (2019) suggested RE as one of the important bands to discriminate several categories of gray mold leaf infections in tomato. In addition, Heim et al. (2019) also reported that the RE and NIR showed high relative importance for the classification of Myrtle Rust on Lemon Myrtle and furthermore, by visually assessing the spectral reflectance signatures of the multispectral image and suggested that multispectral band combinations provide higher accuracy compared to individual band.

Meanwhile, Santoso et al. (2018) showed moderate classification results of different levels of Ganoderma disease severity in oil palm that may due to the lower spatial resolution of the multispectral satellite imagery used compared to high spatial resolution multispectral imagery from UAV that we used in this study. Their results supported the necessity of high spatial resolution image for enhancing disease detection in crops (Yuan et al., 2014; Yamamoto et al., 2017). 
Our findings agreed with Yuan et al. (2014) and Yamamoto et al. (2017) who showed that the combination of two bands of the high spatial resolution multispectral imagery could also increase the accuracy with RE_NIR, which could provide 91.3\% of accuracy. The results agreed with Heim et al. (2019) and Albetis et al. (2019) who reported that the combination of RE and NIR provided high accuracy for discrimination of disease in lemon and grapevines. They also tested the combination of both bands using vegetation indices and were able to enhance the discrimination of disease severity. There are also several studies showing good results from the application of multispectral band combinations for crop diseases (Khairunniza-Bejo et al., 2015; Nainanayeke et al., 2016; De Castro et al., 2015; Xavier et al., 2019).

Khairunniza-Bejo et al. (2015) analysed the ground-based multispectral image for classification of Ganoderma disease in oil palm from frond number nine and found that combination of two bands, which were G_B and G_R, gave a significant difference between healthy and diseased oil palm. Their findings agreed with our results that band combinations have more capability to distinguish between healthy and diseased oil palm.

Other than that, Nainanayake et al. (2016) developed a modified vegetation indices algorithm that combine R, G and two times B band to increase the accuracy of disease detection in coconut tree up to $80 \%$. Meanwhile, Xavier et al. (2019) analysed the G, R and NIR bands individually to classify four levels of Ramulia leaf blight cotton disease and suggested that single band have only showed significant difference between healthy and severe level of the disease and was not accurate for early and moderate severity.

Finally, the results suggested that there is opportunity for multispectral image using UAV for detection of moderate and severe infection of Ganoderma disease in oil palm. For future works, the detection of early infection of Ganoderma disease in oil palm using multispectral image from UAV should be explored using other OBIA methods and also hyperspectral image for early detection of Ganoderma disease in oil palm.

\section{CONCLUSION AND RECOMMENDATION}

In this study, the multispectral image from UAV were analysed using OBIA methods that integrate segmentation and merging with SVM classifier to classify oil palm into three GDSI namely T0, T2 and T3. The results showed different performance of each individual band and different band combinations in classification of the disease severity categories. The individual band showed moderate $(65.5 \%$ $76.2 \%)$ percentage of accuracy for classification of the GDSI. Nevertheless, the combinations of three bands images (G_R_RE, G_R_NIR, R_RE_NIR and R_RE_NIR) had shown good results $(82 \%-91.8 \%)$ with G_R_NIR giving the highest accuracy. This study showed that the three-band combination of multispectral image analysed using OBIA analysis has the capability to detect moderate and severe infection of Ganoderma disease in oil palm. For future works, extensive experiment of OBIA analysis with advanced classifiers such as SVM and RF and advanced template matching algorithm should be conducted to detect early infection of Ganoderma disease in oil palm using multispectral band combinations.

\section{ACKNOWLEDGEMENT}

We would like to thank the Director-General of MPOB for permission to publish this article and the staff of Plant Protection and Biosecurity, MPOB for their support and commitment on this study.

\section{REFERENCES}

Albetis, J; Jacquin, A; Goulard, M; Poilvé, H; Rousseau, J; Clenet, H; Dedieu, G and Duthoit, S (2019). On the potentiality of UAV multispectral imagery to detect flavescence dorée and grapevine trunk diseases. Remote Sens., 11: 1-26.

Ballanti, L; Blesius, L; Hines, E and Kruse, B (2016). Tree species classification using hyperspectral imagery: A comparison of two classifiers. Remote Sens., 8(6)445. DOI:10.3390 / rs8060445.

Blaschke, T (2010). Object-based image analysis for remote sensing. ISPRS J. Photogrammetry and Remote Sens., 65: 2-16.

Campbell, J B (2002). Introduction to Remote Sensing. Third edition. Taylor and Francis, CRC Press, USA. $621 \mathrm{pp}$.

Carter, G A and Knapp, A K (2001). Leaf optical properties in higher plants: Linking spectral characteristics to stress and chlorophyll concentration. American J. Botany, 88: 677-684.

Cho, M A and Skidmore, A K (2006). A new technique for extracting the red edge position from hyperspectral data: The linear extrapolation method. Remote Sens. of Environ., 101: 181-193.

de Castro, A I; Ehsani, R; Ploetz, R C; Crane, J H and Buchanon, S (2015). Detection of laurel wilt disease in avocado using low altitude aerial imaging. PLoS ONE, 10: 1-13. 
Dormann, C F; Elith, J; Bacher, S; Buchmann, C, Carl, G; Carré, G; García Marquéz, J R; Gruber, B; Lafourcade, B; Leitão, P J; Münkemüller, T; McClean, C; Osborne, P E; Reineking, B; Carsten F Dormann; Jane Elith; Sven Bacher; Carsten Buchmann; Gudrun Carl; Carré, G; Bernd Gruber; Bruno Lafourcade; Pedro, J; Tamara Münkemüller; Schröder, B; Skidmore, A K; Zurell, D and Lautenbach, S (2013). Collinearity: A review of methods to deal with it and a simulation study evaluating their performance. Ecography, 36: 027046.

Fahrentrapp, J; Ria, F; Geilhausen, M and Panassiti, B (2019). Detection of gray mold leaf infections prior to visual symptom appearance using a fiveband multispectral sensor. Front. Plant Sci. 10: 628. DOI: 10.3389 / fpls.2019.00628.

Filella, I and Penuelas, J (1994). The red edge position and shape as indicator of plant chlorophyll content, biomass and hydric status. Int. J. Remote Sens., 15: 1459-1470. DOI:10.1029/2005GL022688.

Gholami, R and Fakhari, N (2017). Support vector machine: Principles, parameters and applications. Handbook of Neural Computation (Samui, P; Roy, S; Balas, V eds.). First edition. Academic Press, USA. p. 515-535.

Gupta, R S (2010). Molecular signatures for the main phyla of photosynthetic bacteria and their subgroups. Photosynth. Res., 104: 357-372.

Haboudane, D: Miller, J R: Tremblay, N; ZarcoTejada, P J and Dextraze, L (2002). Integrated narrow-band vegetation indices for prediction of crop chlorophyll content for application to precision agriculture. Remote Sens. of Environ., 81: 416-426.

Haniff, M H; Ismail, S and Idris, A S (2005). Gas exchange responses of oil palm to Ganoderma boninense infection. Asian J. Plant Sci., 4: 438-444.

Heim, R H J; Wright, I J; Scarth, P; Carnegie, A J; Taylor, D and Oldeland, J (2019). Multispectral, aerial disease detection for myrtle rust (Austropuccinia psidii) on a lemon myrtle plantation. Drones, 3: 1-14.

Huang, H; Li, X and Chen, C (2018). Individual tree crown detection and delineation from veryhigh-resolution UAV images based on bias field and marker-controlled watershed segmentation algorithms. IEEE-JSTARS, 11: 2253-2262.

Huang, T; Yang, R; Huang, W; Huang Y and Qiao, $X$ (2018). Detecting sugarcane borer diseases using support vector machine. Inf. Process. Agric., 5: 74-82.
Idris, A S; Ismail, S; Ariffin, D and Ahmad, H (2002). Control of Ganoderma-infected palm - Development of pressure injection and field applications. $M P O B$ Information Series No. 131: 2 pp.

Idris, A S; Nur Rashyeda, R and Madihah A Z (2014). Kawalan Ganoderma sawit menggunakan teknologi. Prosiding Persidangan Pekebun Kecil Sawit Kebangsaan 2014. 11-12 Ogos 2014. Kuching, Sarawak. p. 70-85.

Idris, A S; Nur Rashyeda, R; Mohd Hefni, R; Shamala, S and Norman, K (2016). Standard Operating Procedures (SOP) Guidelines for Managing Ganoderma Disease in Oil Palm. MPOB, Bangi. 41 pp.

Izzuddin, M A; Ezzati, B; Nisfariza, M N; Idris, A S and Alias, S A (2017). Analysis of red, green, blue (RGB) and near infrared (NIR) for detection of Ganoderma disease in oil palm. Proc. of the PIPOC 2017 International Palm Oil Congress: Module 1 - Agriculture, Biotechnology and Sustainability Conference. 14-16 November 2017. Kuala Lumpur Convention Center, Malaysia. p. 90-101.

Jing, X (2009). Segmentation-based image processing system. United States Patent Publication, Pub. No: US 2009/0123070 A1: 1-11.

Johansen, K; Raharjo, T and McCabe, M F (2018). Using multi-spectral UAV imagery to extract tree crop structural properties and assess pruning effects. Remote Sens., 10, 854: 1-21.

Kavzoglu, T and Tonbul, H (2017). A comparative study of segmentation quality for multi-resolution segmentation and watershed transform. $20178^{\text {th }}$ International Conference on Recent Advances in Space Technologies (RAST). 19-22 June 2017. Istanbul, Turkey. p. 113-117.

Khairunniza-Bejo, S; Yusoff, Y; Nik Yusoff, N S; Idris, A S and Izzuddin, M A (2015). Identification of healthy and BSR-infected oil palm trees using color indices. Int. J. Agric. and Biol. Eng., 9: 876-879.

Kohavi, R and Provost, F (1998). On applied research in machine learning. Mach. Learn., 10: 1-6.

Kushairi, A; Loh, S K; Azman, I; Hishamuddin, E; Meilina-Ong, A; Izuddin, Z B M N; Razmah, G; Shamala, S and Parveez, G K A (2018). Oil palm economic performance in Malaysia and R\&D progress in 2017. J. Oil Palm Res. Vol. 30(2): 163-195.

Leckie, D G; Cloney, D and Joyce, S P (2005). Automated detection and mapping of crown discolouration caused by Jack Pine budworm with 
$2.5 \mathrm{~m}$ resolution multispectral imagery. Int. J. Appl. Earth Obs., 5: 61-77.

Lelong, C C D; Roger, J M; Bregand, S; Dubertret, F; Lanore, M; Sitorus, N A; Raharjo, D and Caliman, J P (2010). Evaluation of oil palm fungal disease infestation with canopy hyperspectral reflectance data. Sensors, 10: 734-747.

Li, X and Shao, G (2014). Object-based land-cover mapping with high resolution aerial photography at a county scale in Midwestern USA. Remote Sens., 6: 11372-11390.

Madihah, A Z; Idris, A S and Rafidah, A R (2014). Polyclonal antibodies of Ganoderma boninense isolated from Malaysia oil palm for detection of basal stem rot disease. Afr. J. Agric. Res., 13: 34553463. DOI:10.5897/A.

Momeni, R; Aplin, P and Boyd, D S (2016). Mapping complex urban land cover from spaceborne imagery: the influence of spatial resolution, spectral band set and classification approach. Remote Sens., 8: $1-23$.

Mahlein, A K; Steiner, U; Dehne, H W and Oerke, E C (2010). Spectral signatures of sugar beet leaves for the detection and differentiation of diseases. Precis. Agric., 11: 413-431.

Mokhtari, M H; Busu, I; Mokhtari, H; Zahedi, G; Sheikhhatter, L and Movahed, M A (2013). Neural network and multiple linear regression for estimating surface albedo from aster visible and near-infrared spectral bands. Earth Interact., 17: $1-20$.

Mulley, M; Kooistra, L and Bierens, L (2019). Highresolution multisensor remote sensing to support date palm farm management. Agriculture, 9: 1-22.

Nainanayake, A D; Gunathilake, J; Kumarathunga, M D P; Gunawardena, N P M and Wijesekara, H T $R$ (2016). Limitation in the use of spectral analysis to detect Weligama coconut leaf wilt disease affected palms in Southern Sri Lanka. COCOS, 22: 13-24.

Noi, P T and Kappas, M (2018). Comparison of random forest, k-nearest neighbor, and support vector machine classifiers for land cover classification using Sentinel-2 imagery. Sensors, 18: 1-20.

Nuranis, I; Kamaruzaman, S; Khairulmazmi, A; Mohd Shukri, I; Zulkifli, H and Idris, A S (2016). Leaf nutrient status in relation to severity of Ganoderma infection in oil palm seedlings artificially infected with Ganoderma boninense using root inoculation technique. Oil Palm Bulletin No. 72: 25-31.
Pal, M and Mather, P M (2005). Support vector machines for classification in remote sensing. Int. J. Remote Sens., 26(5): 1007-1011.

Patel, N and Kaushal, B (2011). Classification of features selected through Optimum Index Factor (OIF) for improving classification accuracy. J. For. Res., 22: 99-105.

Parisa, A; Muharam, F M; Ahmad, K; Mansor, S and Idris, A S (2017). Early detection of Ganoderma basal stem rot of oil palms using artificial neural network spectral analysis. Plant Dis., 101: 1009-1016.

Pix4D (2019). Parrot Sequoia+. https:/ / www.pix4d. com/product/sequoia, accessed on 25 March 2019.

Pujari, J D; Yakkundimath, R and Abdulmunaf, S B (2016). SVM and ANN based classification of plant diseases using feature reduction technique. Int. J. Artif. Intell. T., 3: 6-14.

Puliti, S; Talbot, B and Astrup, R (2018). Treestump detection, segmentation, classification, and measurement using Unmanned Aerial Vehicle (UAV) imagery. Forests, 9: 1-14.

Rahman, H; Ch, NJ; Manzoor, S; Najeeb, F; Siddique, M Y and Khan, R A (2017). A comparative analysis of machine learning approaches for plant disease identification. Adv. Life Sci., 4: 120-126.

Rees, R W; Flood, J; Hasan, Y and Cooper, R M (2007). Effects of inoculum potential, shading and soil temperature on root infection of oil palm seedlings by the basal stem rot pathogen Ganoderma boninense. Plant Pathol., 56: 862-870.

Rees, W G (2013). Physical Principles of Remote Sensing. Third edition. Cambridge University Press, United Kingdom. 362 pp.

Richards, J A (2013). Remote Sensing Digital Image Analysis. $5^{\text {th }}$ edition. Springer-Verlag Berlin Heidelberg. 494 pp. 10.1007/978-3-642-30062-2.

Rizeei, H M; Shafri, H Z M; Mohamoud, M A; Pradhan, B and Kalantar, B (2018). Oil palm counting and age estimation from worldview-3 imagery and LiDAR data using an integrated OBIA height model and regression analysis. J. Sensors, 2018: 1-13.

Roerdink, J B T M and Meijster, A (2001). The watershed transform: Definitions, algorithms and parallelization strategies. Fundam. Inform., 41: 187228.

Roslan, A and Idris, A S (2012). Economic impact of Ganoderma incidence on Malaysian oil palm 
plantation - A case study in Johor. Oil Palm Ind. Econ. J. Vol. 12: 24-30.

Salgadoe, A S A; Robson, A J; Lamb, D W; Dann, E K and Searle, C (2018). Quantifying the severity of phytophthora root rot disease in avocado trees using image analysis. Remote Sens., 10: 1-17.

Santoso, H; Gunawan, T; Jatmiko, R H; Darmosarkoro, W and Minasny, B (2011). Mapping and identifying basal stem rot disease in oil palms in North Sumatra with QuickBird imagery. Precis. Agric., 12: 233-248.

Santoso, H; Tani, H; Wang, X; Prasetyo, A K and Sonobe, R (2018). Classifying the severity of basal stem rot disease in oil palm plantations using WorldView-3 imagery and machine learning algorithms. Int. J. Remote Sens. DOI: 10.1080/01431161.2018.1541368.

Shafri, HZ M and Hamdan, N (2009). Hyperspectral imagery for mapping disease infection in oil palm plantation using vegetation indices and red edge techniques. Am. J. Appl. Sci., 6: 10311035.

Shafri, H Z M and Ramle, F S H (2009). A comparison of support vector machine and decision tree classifications using satellite data of Langkawi Island. Inf. Technol. J., 8: 64-70.

Shao, Y and Lunetta, R S (2012). Comparison of support vector machine, neural network, and CART algorithms for the land-cover classification using limited training data points. ISPRS J. Photogramm, 70: 78-87.

Thenkabail, P S; Lyon, J G and Huete, A (2016). Advances in hyperspectral remote sensing of vegetation and agricultural cropland. Hyperspectral Remote Sensing of Vegetation (Thenkabail, P S and Lyon, J G eds.). First edition. CRC Press, USA. $782 \mathrm{pp}$.

Turkoglu, M and Hanbay, D (2019). Plant disease and pest detection using deep learning-based features. Turk. J. Electr. Eng. \& Comp. Sci., 27: 16361651.

Viera, A J and Garrett, J M (2005). Understanding interobserver agreement: The Kappa statistic. Family Medicine, 37: 360-363.

Vincini, M and Frazzi, E (2011). Comparing narrow and broad-band vegetation indices to estimate leaf chlorophyll content in planophile crop canopies. Precis. Agric., 12: 334-344.

Xavier, T W F; Souto, R N V; Statella, T; Galbieri, R; Santos, E S; Suli, G S and Zeilhofer, P (2019). Identification of Ramularia leaf blight cotton disease infection levels by multispectral, multiscale UAV imagery. Drones, 3: 33.

Xie, Z; Chen, Y; Lu, D; Li, G and Chen, E (2019). Classification of land cover, forest, and tree species classes with ziyuan-3 multispectral and stereo data. Remote Sens., 11: 1-27.

Yamamoto, K; Togami, $\mathrm{T}$ and Yamaguchi, N (2017). Super-resolution of Plant Disease Images for the Acceleration of Image-based Phenotyping and Vigor Diagnosis in Agriculture. Sensors, 17: 2557.

Yang, C; Everitt, J H and Fernandez, C J (2010). Comparison of airborne multispectral and hyperspectral imagery for mapping cotton root rot. Biosyst. Eng., 107: 131-139.

Yuan, L; Zhang, J; Shi, Y, Nie C; Wei, L and Wang, $\mathrm{J}$ (2014). Damage mapping of powdery mildew in winter wheat with high-resolution satellite image. Remote Sens., 6: 3611-3623. 